\title{
Matéria
}

Revista Matéria, v. 14, n. 4, pp. 1088 - 1100, 2009

ISSN 1517-7076

http://www.materia.coppe.ufrj.br/sarra/artigos/artigo11055

\section{Secagem e retração volumétrica de tijolos cerâmicos maciços e vazados: uma investigação teórica e experimental}

BATISTA,V.R., NASCIMENTO, J.J.S., LIMA, A.G.B. de

Unidade Acadêmica de Engenharia de Materiais, Centro de Ciências e Tecnologia, Universidade Federal de Campina Grande, Av. Aprígio Veloso, 882, Bodocongó - CEP 58429-900 - Campina Grande, PB, Brasil. e-mail: valmir5@yahoo.com.br, jefferson@dem.ufcg.edu.br, gilson@dem.ufcg.edu.br

\section{RESUMO}

A indústria cerâmica apresenta processos industriais com um grande consumo de energia e elevado impacto ambiental. A grande maioria destas indústrias está desenvolvendo produtos de baixa qualidade devido a processos inadequados de secagem e queima. Sendo assim, a finalidade deste estudo é contribuir para a melhoria da qualidade do processo de secagem apresentando um estudo experimental da secagem de amostras de argila para cerâmica vermelha (blocos vazados e tijolos maciços), com diferentes dimensões e umidades iniciais. Nos processos de secagem, várias temperaturas e umidades relativas do ar foram usadas, e várias curvas da cinética de secagem e de retração volumétrica foram obtidas. Equações matemáticas para descrever a perda de água e variações dimensionais durante o processo de secagem foram propostas Verificou-se que o processo de secagem ocorreu no período de taxa decrescente e o encolhimento apresentou dois períodos distintos.

Palavras-chaves: Secagem, encolhimento, blocos vazados, tijolos maciços, experimental.

\section{Drying and volumetric retraction of solid and hollow ceramic bricks: a theoretical and experimental investigation}

\section{ABSTRACT}

The ceramic industry presents industrial processes with a large consumption of energy and high environmental impact. These industries are developing products of low quality due to inadequate drying and firing processes. Therefore, the purpose of this study is to contribute for the improvement of drying process by presenting a drying experimental study of the samples of clay for red ceramics (hollow and solid bricks) with different dimensions and initial moisture contents. In the drying processes, several air temperatures and air relative humidity were used, and thus several curves of the drying kinetics and volumetric retraction are shown and analyzed. Mathematical equations for predict lost of water and dimension variations during the process were obtained. It was verified that drying process takes place in the falling rate period and shrinkage happens in two distinct periods.

Keywords: Drying, shrinkage, hollow blocks, ceramic bricks, experimental.

\section{INTRODUÇÃO}

Investigações arqueológicas realizadas até o momento, indicam que os primeiros tijolos empregados na construção foram fabricados na Mesopotâmia e datam de 4000 a.C.. Neste período, os tijolos eram utilizados no estado seco e não queimados. Os primeiros tijolos queimados datam de 3000 a.C. e eram empregados para revestimentos externos e mais freqüentemente como muros de proteção [1]. No Brasil, a fabricação de tijolos e outros produtos afins ocorreram no início do século passado. Entretanto, somente na década de 1930 é que foram fabricados os primeiros tijolos furados através de processos mecanizados. Atualmente, a cerâmica de construção brasileira ocupa um lugar de destaque na economia do país. Durante um período de 55 à 58 séculos de produção de tijolos não ocorreram mudanças tecnológicas importantes. Somente nos últimos 40 ou 50 anos é que a tecnologia de fabricação de tijolos passou por um processo de desenvolvimento associado às inovações. No entanto, considerando também as variáveis operacionais, se 
torna cada vez mais importante, quando se considera produtividade e qualidade, o conhecimento das variáveis de controle do processo [1].

A extração e tratamento das matérias primas para cerâmica são operações importantes na fabricação de produtos cerâmicos. O processo de produção de tijolos cerâmicos vazados segue as seguintes etapas subseqüentes: extração da argila; beneficiamento; extrusão; secagem; queima; seleção e estoque. Dentre estas, a etapa de secagem merece especial atenção. Isto porque, logo após a conformação da peça cerâmica, a água está distribuída, quase que homogeneamente, entre as partículas de argila e outros componentes da argila. Esta água precisa ser retirada cuidadosamente e de forma homogênea, já que a saída da água faz com que as partículas de argila e outros componentes se aproximem, diminuindo o tamanho da peça (fenômeno este conhecido por encolhimento ou retração volumétrica). Se essa diminuição não for uniforme poderá provocar trincas ou, em casos extremos a quebra da peça. A água, presente no sistema, começa a evaporar pela superfície da peça, em seguida, a água que se encontra no interior da peça migra para a superfície para também evaporar, entretanto, em temperaturas mais elevadas, a evaporação da água pode ocorrer nos próprios poros da peça. Portanto, quanto maior as dimensões da peça mais demorado e difícil é o seu processo de secagem, contudo, desde que a relação área/volume da peça e as condições operacionais dominem o processo, esta afirmação é dependente do tipo e forma do produto. Neste contexto, é fundamental conhecer os efeitos da secagem e o seu controle, uma vez que estes alteram as propriedades físicas e químicas do produto, e tais alterações afetam sensivelmente o processo de transferência de calor e massa [2].

Diante do cenário apresentado, pode-se definir a secagem como sendo um processo que envolve simultaneamente transferência de calor, massa e variações dimensionais em corpos porosos. A otimização do processo de secagem se dá pelo controle da taxa de secagem, prevenindo rachaduras, fissuras e deformações nos materiais. Neste sentido, vários pesquisadores desenvolveram estudos sobre secagem de argila [므-16], e outros a secagem de sólidos cerâmicos incluindo o fenômeno de encolhimento, que altera a cinética de secagem e as dimensões do sólido [ㅁ- $\underline{6}, \underline{17}-\underline{22}]$. O fenômeno acontece simultaneamente com o transporte de umidade e calor, e é mais intenso em materiais cerâmicos com umidade inicial alta, e principalmente em produtos de granulação fina. Como mencionado, dependendo das condições de secagem, da estrutura do material e da geometria do produto, o fenômeno de variações dimensionais, pode causar rachaduras, deformações e até mesmo fraturas dentro dos sólidos. Então torna-se importante estudar as formas geométricas dos materiais cerâmicos e sua relação com a perda de água durante o processo de secagem.

Comercialmente existem duas geometrias diferentes de tijolos: os tijolos maciços e os blocos cerâmicos ou tijolos furados. O ideal para a especificação de um tijolo é o atendimento às normas brasileiras para tijolos maciços: (NBR 6460/83, NBR 7170/83, NBR 8041/83) e blocos vazados (NBR 6461/83, NBR 8043/83, NBR 7171/92, NBR 8042/92). Porém, em geral, não se encontram no mercado produtos de conformidade com as mesmas, pelo próprio caráter ainda artesanal do produto, o que evidencia a necessidade de estudos mais apurados nessa área.

Se por um lado existe o problema da falta de padronização dos produtos cerâmicos, por outro, na literatura, há escassas informações sobre os coeficientes de encolhimento, como também de relações matemáticas entre difusividade de massa, encolhimento e densidade de materiais cerâmicos. Resultados de curvas de encolhimento linear versus teor de umidade para argila, podem ser encontradas na literatura [ㄱ-모, 23], contudo, novos estudos precisam ser conduzidos para ampliar o entendimento do fenômeno e otimizar o processo de secagem de produtos cerâmicos Neste sentido, este trabalho tem como objetivo estudar experimentalmente a cinética de secagem e as variações dimensionais de tijolos cerâmicos maciços e vazados em várias condições do ar de secagem.

\section{MATERIAIS E MÉTODOS}

\subsection{Material}

Para confecção das amostras, foi usado uma argila para cerâmica vermelha oriunda do município de Itaporanga-PB, Brasil. 


\subsection{Metodologia experimental}

\subsubsection{Análise mineralógica}

Para a realização da análise mineralógica da argila, a amostra foi secada em estufa a $110^{\circ} \mathrm{C}$ e passada em peneira $A B N T n^{\circ} 200(0,074 \mathrm{~mm})$. Em seguida, foi submetida a uma difração de raios-X em um

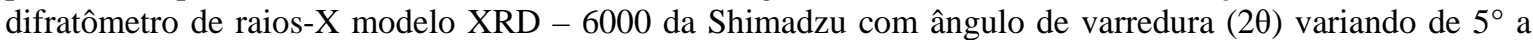
$80^{\circ}$. Os valores das distâncias interplanares basais foram obtidos através da seguinte relação de Bragg simplificada: $n \lambda=2 d$ 'sen $(\theta)$, onde $\lambda=1,5418 \AA$ é o comprimento de onda ou radiação do cobre, d' é a distância interplanar basal (característica para cada fase cristalina) e n é a “ordem de reflexão" que neste caso será considerado igual a um, porque se fez correspondência entre um dado plano de índices (hkl) e um único ângulo $\theta$.

\subsubsection{Análise térmica}

Os ensaios térmicos das amostras da argila foram realizados em um Sistema de Análises Térmicas da BP-Engenharia, modelo AS - 500C com sistema RB - 300 sob uma taxa de aquecimento de $12,5^{\circ} \mathrm{C} / \mathrm{min}$ até a temperatura de $1000^{\circ} \mathrm{C}$. O padrão utilizado foi o oxido de alumínio $\left(\mathrm{Al}_{2} \mathrm{O}_{3}\right)$, e não houve controle da atmosfera interna do equipamento.

\subsubsection{Preparação dos corpos de prova de argila}

Os blocos cerâmicos vazados com seis furos (cerâmica vermelha) foram moldados por extrusão em uma extrusora de laboratório tipo Verdés, modelo BR 051, enquanto que os tijolos cerâmicos maciços foram moldados por prensagem na forma paralelepipedal a uma pressão de 19,61 MPa. A quantidade de água usada para a confecção da amostra foi baseada nos limites de Atterberg (limites de consistência) relativo à água de extrusão, que se situa um pouco acima do limite de plasticidade. Na Figura 1 ilustra-se a geometria de ambos os corpos de prova.

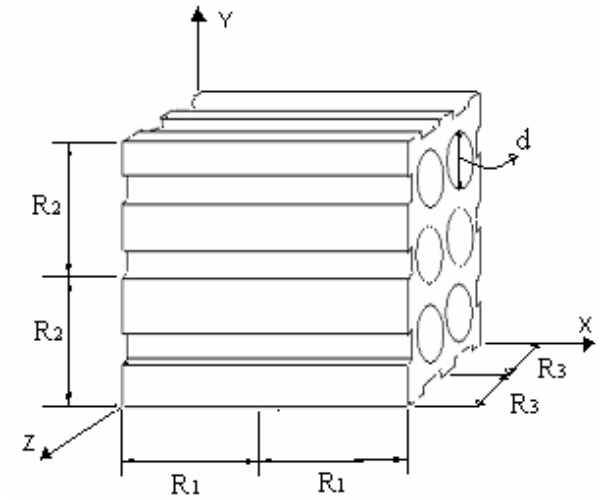

(a)

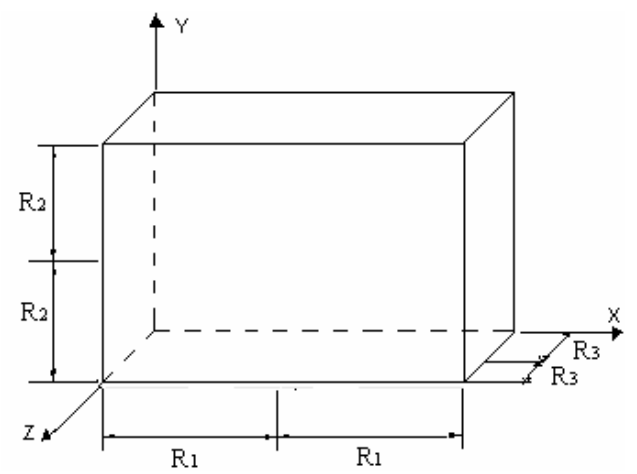

(b)

Figura 1: Características geométricas dos corpos de prova e suas dimensões: a) tijolo furado e b) tijolo maciço.

\subsubsection{Secagem dos corpos de prova de argila}

Os tijolos foram secados em diferentes temperaturas e umidades relativas colocando-os numa estufa sem circulação de ar. Em cada experimento as amostras foram pesadas e suas dimensões medidas, em intervalos de 10 minutos, para as três primeiras medidas; o restante das medidas foram feitas em intervalos de 30 minutos, durante o processo de secagem. As massas das amostras foram obtidas numa balança eletrônica com precisão de $\pm 0,01 \mathrm{~g}$, enquanto que as dimensões das amostras foram medidas usando um paquímetro digital com precisão de $\pm 0.01 \mathrm{~mm}$. A umidade relativa do ar foi calculada usando o software CATT a partir das temperaturas de bulbo seco e bulbo úmido do ar de secagem, obtidas com o auxílio de um higrômetro.

As experiências de secagem contínua terminaram quando a massa das amostras alcançou um valor constante. Para obter o valor da umidade de equilíbrio e a massa das amostras totalmente secas, estas permaneceram na estufa na mesma temperatura de secagem durante 48 horas. Todos os testes foram 
executados a uma pressão atmosférica. A Tabela 1 apresenta os dados de tijolos cerâmicos e todas as condições de secagem que foram usadas neste estudo, onde $M o$ é o teor de umidade inicial, $M_{f}$ é o teor de umidade final, $M e$ é o teor de umidade de equilíbrio, $2 \mathrm{R}_{1}, 2 \mathrm{R}_{2}$ e $2 \mathrm{R}_{3}$, correspondem respectivamente a comprimento, largura e altura.

O teor de umidade médio em base seca foi obtido a partir da seguinte equação matemática:

$$
M=\frac{m_{a}}{m_{s}}
$$

onde $m_{a}$ e $m_{s}$ são, respectivamente, a massa de água e massa do produto totalmente seco.

Tabela 1: Condições experimentais usadas neste trabalho.

\begin{tabular}{|c|c|c|c|c|c|c|c|c|c|c|c|}
\hline & \multirow[b]{2}{*}{ Amostra } & \multicolumn{2}{|c|}{ Ar } & \multicolumn{8}{|c|}{ Tijolos cerâmicos } \\
\hline & & $\begin{array}{c}\mathbf{T} \\
\left({ }^{\circ} \mathbf{C}\right)\end{array}$ & $\begin{array}{l}\text { UR } \\
\text { (\%) }\end{array}$ & $\begin{array}{c}\text { Mo } \\
\text { (b.s) }\end{array}$ & $\begin{array}{c}\mathbf{M}_{\mathrm{f}} \\
\text { (b.s }\end{array}$ & $\begin{array}{c}\text { Me } \\
\text { (b.s) }\end{array}$ & $\begin{array}{c}2 \mathrm{R}_{1}(\mathrm{~m}) \\
\times 10^{3}\end{array}$ & $\begin{array}{c}2 R_{2}(\mathrm{~m}) \\
\times 10^{3}\end{array}$ & $\begin{array}{r}2 \mathbf{R}_{3}(\mathbf{m}) \\
\times 10^{3} \\
\end{array}$ & $\begin{array}{l}\mathrm{d}(\mathrm{m}) \\
\times 10^{3}\end{array}$ & $\begin{array}{c}t \\
(\mathrm{~min})\end{array}$ \\
\hline \multirow{4}{*}{$\begin{array}{c}\text { Blocos } \\
\text { vazados }\end{array}$} & CPV170 & 70 & 8,71 & 0,2222 & 0,0322 & 0,0048 & 65,90 & 57,88 & 35,19 & 11,03 & 270 \\
\hline & \begin{tabular}{|l} 
CPV190 \\
\end{tabular} & 90 & 3,28 & 0,2200 & 0,0092 & 0,0035 & 64,21 & 57,68 & 35,03 & 10,87 & 270 \\
\hline & \begin{tabular}{|l|} 
CPV290 \\
\end{tabular} & 90 & 3,28 & 0,2200 & 0,0064 & 0,0018 & 64,1 & 57,79 & 35,06 & 11,88 & 270 \\
\hline & CPV1110 & 110 & 2,01 & 0,2225 & 0,0133 & 0,0006 & 66,04 & 58,11 & 35,03 & 11,37 & 240 \\
\hline \multirow{4}{*}{$\begin{array}{l}\text { Tijolos } \\
\text { maciços }\end{array}$} & CPM160 & 60 & 14,00 & 0,0780 & 0,0111 & 0,0053 & 120,64 & 60,24 & 7,97 & -- & 330 \\
\hline & CPM180 & 80 & 6,00 & 0,0870 & 0,0033 & 0,0011 & 120,12 & 60,09 & 6,75 & -- & 330 \\
\hline & СРМ280 & 80 & 6,00 & 0,094 & 0,0049 & 0,0009 & 120,43 & 60,27 & 7,69 & -- & 330 \\
\hline & CPM1110 & 110 & 2,00 & 0,1020 & 0,0075 & 0,0043 & 120,72 & 60,31 & 6,57 & -- & 240 \\
\hline
\end{tabular}

*Nesta tabela, por exemplo, o código CPV170 representa corpo de prova vazado 1 realizada a $70{ }^{\circ} \mathrm{C}$, $\mathrm{t}$ representa o tempo total de secagem. "bs” significa base seca (kg de água / kg de matéria seca). As dimensões do tijolo refrem-se às condições iniciais.

\subsection{Modelo matemático}

\subsubsection{Variações dimensionais}

De acordo com a literatura [24], a seguinte equação foi utilizada para obter as mudanças de volume do sólido para cada tempo, durante o processo de secagem:

$$
V_{t}=V_{0}\left(\beta_{1}+\beta_{2} M_{m e d}\right)
$$

Em t $=0, M_{\text {med }}=M_{0}$, e $V_{t}=V_{o}$, então tem-se que $\beta_{1}=1-\beta_{2} M_{o}$. Logo a equação (2) pode ser escrita como segue:

$$
\frac{V_{t}}{V_{0}}=1-\beta_{2}\left(M_{O}-M_{\text {med }}\right)
$$

Definindo alguns parâmetros descritos abaixo, a equação (3) pode ser reescrita como segue:

$$
\frac{V_{t}}{V_{0}}=\beta_{3}+\beta_{4} M_{m e d} *
$$


onde $\beta_{3}=\beta_{1}+\beta_{2} M_{\mathrm{e}}$ e $\beta_{4}=\beta_{2}\left(M_{0}-M_{e}\right)$ são os coeficientes de encolhimento volumétrico (que foram obtidos usando o método de Rosembrock e quasi-Newton com critério de convergência de 0,001, a partir do ajuste do modelo aos dados experimentais do teor de umidade e dimensões do sólido) e $M_{\text {med }} *=\left(M_{\text {med }}-M_{e}\right) /\left(M_{o}-M_{e}\right)$ é o teor de umidade médio adimensional.

Considerando que o encolhimento é isotrópico, que a taxa de variação de $\left(\mathrm{R}_{1}\right)_{\mathrm{t}},\left(\mathrm{R}_{2}\right)_{\mathrm{t}}$ e $\left(\mathrm{R}_{3}\right)_{\mathrm{t}}$ (Figura 1) relacionam-se entre si de tal forma que esta relação permaneça constante, e que os diâmetros dos seis furos sejam idênticos e com iguais retrações, pode-se mostrar que o volume de um bloco cerâmico com seis furos é dado pela diferença entre o volume total e o volume formado pelos seis furos, como mostrado na equação (5) a seguir:

$$
V_{t}=8\left(R_{1 t} R_{2 t} R_{3 t}\right)-\left[6\left(\pi \frac{d_{t}^{2}}{4} 2 R_{1 t}\right)\right]
$$

Reformulando a equação (5), tem-se:

$$
V_{t}=R_{1}\left(8 R_{2} R_{3 t}-3 \pi d_{t}^{2}\right)
$$

Vale salientar que para tijolos maciços, $d_{t}=0$.

A área superficial do bloco vazado é dada pela soma das áreas de todas as faces, inclusive a soma das áreas das paredes internas dos seis furos. Esta grandeza é calculada pela equação (7) a seguir.

$$
S_{t}=2\left(2 R_{1 t} 2 R_{2 t}\right)+2\left(2 R_{1 t} 2 R_{3 t}\right)+\left[2\left(2 R_{2 t} 2 R_{3 t}\right)-\left(12 \pi \frac{d_{t}^{2}}{4}\right)\right]+6\left(2 \pi \frac{d_{t}}{2} 2 R_{1 t}\right)
$$

Reformulando a equação (7), tem-se:

$$
S_{t}=8\left[R_{1 t}\left(R_{2 t}+R_{3 t}+3 \pi \frac{d_{t}}{2}\right)+R_{2 t} R_{3 t}-3 \pi \frac{d_{t}^{2}}{8}\right]
$$

\subsubsection{Cinética de secagem}

Para descrever a secagem em muitos processos industriais, várias equações empíricas foram propostas por diversos autores [24]. Neste contexto, alguns pesquisadores têm usado solução em série da equação de difusão para obter a cinética de secagem como segue:

$$
\mathrm{M}_{\text {med }} *=\sum_{\mathrm{i}=1}^{\mathrm{N}} \mathrm{A}_{1} \exp ^{\left(-\mathrm{K}_{\mathrm{i}} \mathrm{t}\right)}
$$

onde $A_{i}$ e $K_{i}$ são constantes, e $N$ é o número de termos da série.

Os termos desta série convergente diminuem com um aumento de $N$ e $t$. Várias aproximações e variações do modelo de difusão foram usadas para predizer a taxa de secagem de diferentes sólidos, porém, relativamente poucos estudos são relacionados a materiais cerâmicos. Assim sendo, foi proposta uma forma aproximada da equação (9) quando apenas três termos da série infinita são usadas. Desta maneira, pode-se escrever:

$$
M_{\text {med }} *=A_{1} \exp ^{\left(-K_{1} t\right)}+A_{2} \exp ^{\left(-K_{2} t\right)}+A_{3} \exp ^{\left(-K_{3} t\right)}
$$

As constantes $A_{i}$ e $K_{i}$ foram determinadas ajustando esta equação aos dados experimentais do teor de umidade para cada condição de secagem, usando o método Rosembrock e quasi-Newton com critérios de convergência de 0,001 . 


\section{RESULTADOS E DISCUSSÃO}

\subsection{Análise química e mineralógica da argila}

A composição química da argila usada para confecção dos tijolos cerâmicos esta apresentada na Tabela 2.

Tabela 2: Composição química da argila

\begin{tabular}{|c|c|c|c|c|c|c|c|c|c|}
\hline Componentes & $\mathbf{R I}$ & $\mathbf{P R}$ & $\mathbf{S i O}_{2}$ & $\mathbf{F e}_{2} \mathbf{O}_{\mathbf{3}}$ & $\mathbf{A l}_{2} \mathbf{O}_{3}$ & $\mathbf{C a O}$ & $\mathbf{M g O}$ & $\mathbf{N a}_{2} \mathbf{O}$ & $\mathbf{K}_{\mathbf{2}} \mathbf{O}$ \\
\hline Composição (\%) & 1,10 & 7,82 & 52,70 & 7,58 & 23,97 & 0,56 & 4,04 & 0,62 & 1,25 \\
\hline
\end{tabular}

RI - Resíduo insolúvel; $\quad$ PR - Perda ao rubro

Analisando o resultado da composição química da argila (Tabela 2), verifica-se que a mesma apresenta teor de sílica $\left(\mathrm{SiO}_{2}\right) 52,70 \%$, proveniente dos minerais argilosos e da sílica livre. O teor de alumina $\left(\mathrm{Al}_{2} \mathrm{O}_{3}\right)$ é $23,97 \%$, oriunda do argilomineral caulinita e da mica. O teor de Ferro $\left(\mathrm{Fe}_{2} \mathrm{O}_{3}\right)$ superior a $7 \%$, indica que a argila apresentará, após a queima, a coloração vermelha, principalmente devido a oxidação do composto de ferro que ao final apresenta-se sob a forma de óxido férrico. A intensidade da coloração vermelha depende da quantidade de óxido férrico presente.

A Figura 2 apresenta o difratograma obtido para a argila estudada, onde pode-se verificar a presença de montmorilonita (d' = 14,718), ilita ( $\mathrm{d}^{\prime}=10,024$, d' $\left.=4,989\right)$, caulinita $\left(\mathrm{d}^{\prime}=7,213\right.$, d' $\left.=3,189\right)$, quartzo (d' $\left.=3,3458, d^{\prime}=4,237, d^{\prime}=2,457\right)$ e mica $\left(d^{\prime}=, 2,459, d^{\prime}=3,779\right)$, sendo d' a distância interplanar em angstroms. Picos secundários desses argilominerais também foram detectados.

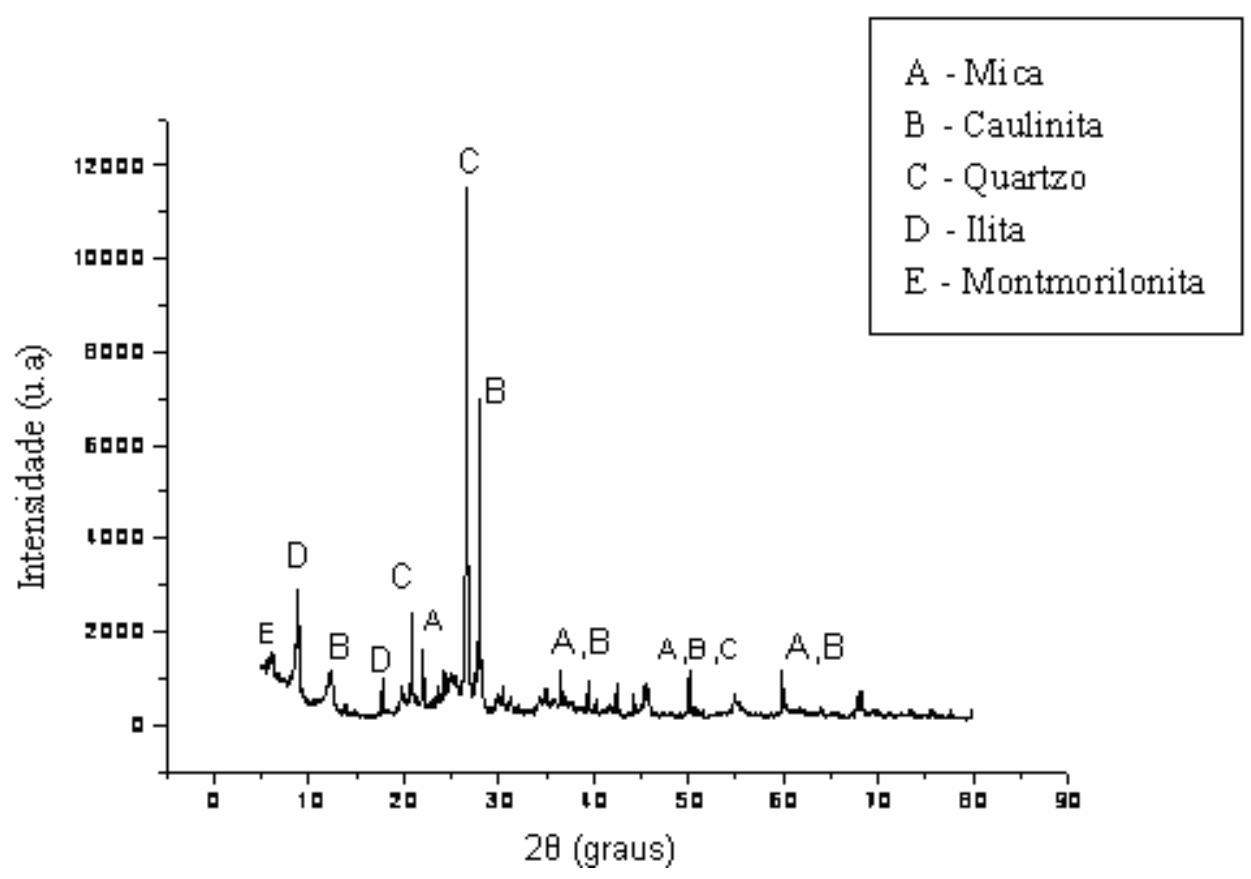

Figura 2: Difratograma de raios-X para argila

\subsection{Análise térmica da argila}

As curvas da análise térmica diferencial (DTA) e análise térmica gravimétrica (TGA) estão mostradas na Figura 3. Na DTA, observa-se a existência de picos térmicos significativos. Os picos que ocorrem entre 110 e $200^{\circ} \mathrm{C}$ são devidos à presença de água livre e água absorvida. Entre as temperaturas de $200^{\circ} \mathrm{C} \mathrm{e} 502^{\circ} \mathrm{C}$, ocorrem bandas exotérmicas, provavelmente, devido às reações da matéria orgânica. Um pico endotérmico é observado entre 502 e $580^{\circ} \mathrm{C}$, que está associado à eliminação das hidroxilas da argila e transformação da caulinita em metacaulinita. Um pico exotérmico pode ser observado na temperatura de $588^{\circ} \mathrm{C}$, o qual está associado à presença da grafite. Na temperatura de $909^{\circ} \mathrm{C}$, observou-se um pico exotérmico, que está associado a reorganização do material, com formação de fases cristalinas, devido à nucleação da mulita. 
Analisando a TGA da amostra, verifica-se uma perda de massa total de 9,0\%. Na faixa de temperatura compreendida entre 100 e $200^{\circ} \mathrm{C}$, ocorre uma perda de massa correspondente a $1,0 \%$, característicos da perda de água. Na faixa de temperatura, compreendida entre 200 e $600^{\circ} \mathrm{C}$, verifica-se uma queda de massa devido, provavelmente, à perda de matéria orgânica e hidroxilas, correspondendo a uma perda de 6,8\% da massa total. De 600 à $1000^{\circ} \mathrm{C}$ ocorre uma perda de massa de $1,8 \%$ da massa total devido a perda de matéria orgânica na forma de grafite e pequenas quantidades de carbonetos usualmente presentes nas matérias primas para cerâmica vermelha e não detectáveis na DTA.

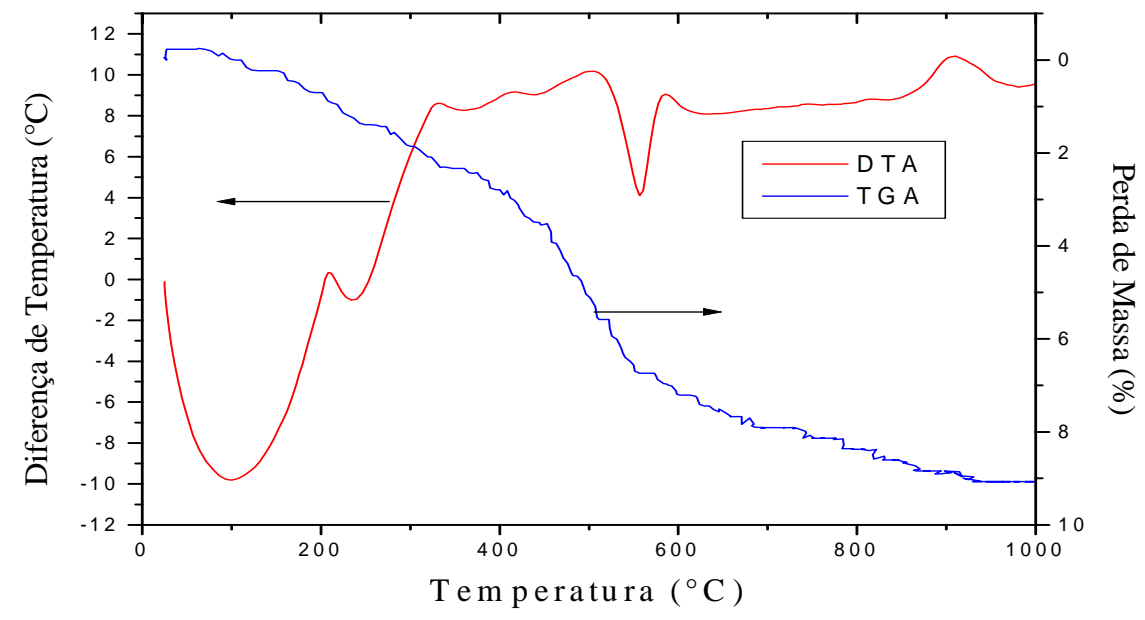

Figura 3: Análise térmica da argila

\subsection{Variações dimensionais}

Os valores da estimativa dos coeficientes de encolhimento da equação (4) aplicada a tijolos cerâmicos para oito experimentos de secagem são apresentados na Tabela 3. Os coeficientes de correlação em todas as experiências chegam muito próximo de 1,0. As curvas de comparação entre os dados de encolhimento experimentais e preditos pela equação proposta, para blocos vazados e maciços, são mostradas nas Figuras 4 - 7.

Tabela 3: Coeficientes de encolhimento volumétrico e de correlação (R) para as experiências de secagem.

\begin{tabular}{|c|c|c|c|c|c|c|c|}
\hline & \multirow{2}{*}{ Amostras } & \multicolumn{3}{|c|}{$1^{\circ}$ passo de encolhimento } & \multicolumn{3}{|c|}{$2^{\circ}$ passo de encolhimento } \\
\hline & & $\beta_{3}$ & $\beta_{4}$ & $\mathbf{R}$ & $\beta_{3}$ & $\beta_{\Delta}$ & $\mathbf{R}$ \\
\hline \multirow{4}{*}{$\begin{array}{c}\text { Blocos } \\
\text { vazados }\end{array}$} & CPV170 & 0,820331 & 0,176762 & 0,977 & 0,888358 & 0,022322 & 0,943 \\
\hline & CPV190 & 0,811631 & 0,167454 & 0,941 & 0,878121 & 0,02324 & 0,937 \\
\hline & CPV290 & 0,921929 & 0,07792 & 0,987 & 0,945556 & 0,022137 & 0,981 \\
\hline & CPV1110 & 0,871371 & 0,127998 & 0,669 & 0,916576 & 0,027362 & 0,984 \\
\hline \multirow{4}{*}{$\begin{array}{l}\text { Tijolos } \\
\text { maciços }\end{array}$} & CPM160 & 0,9803167 & 0,0173372 & 0,963 & 0,9800886 & 0,0196303 & 0,821 \\
\hline & CPM180 & 0,977948 & 0,0207332 & 0,99 & 0,97669 & 0,0547766 & 0,934 \\
\hline & CPM280 & 0,978119 & 0,020481 & 0,99 & 0,976069 & 0,0530033 & 0,922 \\
\hline & CPM1110 & 0,941138 & 0,0505213 & 0,886 & 0,9557545 & 0,0265298 & 0,941 \\
\hline
\end{tabular}

Analisando as Figuras 4-7 verifica-se que no início do processo de secagem, há uma grande remoção de umidade, assim, as dimensões dos sólidos mudam com velocidade mais elevada, decrescendo com o passar do tempo até chegar à zero. O ponto onde o encolhimento apresenta um novo comportamento depende das diferentes composições do material. Pode-se verificar ainda a existência de dois períodos com mudanças volumétricas. Este comportamento está em concordância com os resultados da literatura [므- $\underline{6}$, $\underline{25}-$ 26]. O ponto onde as curvas interceptam é chamado teor de umidade crítico [7]. Porém, neste estudo não foi encontrado nenhum período de secagem constante pelo baixo teor de umidade inicial das amostras, e então, a denominação de teor de umidade crítico pode não ser adequada para o ponto de interseção das retas. 


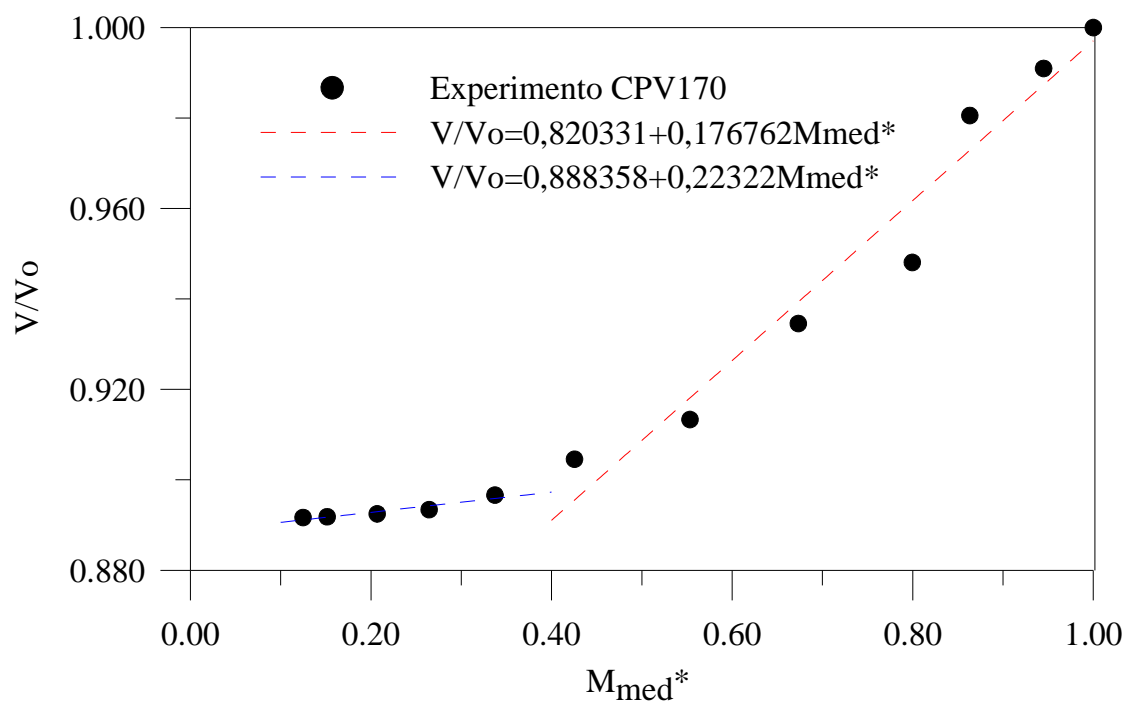

Figura 4: Comparação entre os volumes predito e experimental de tijolos cerâmicos vazados obtidos durante a secagem à $\mathrm{T}=70^{\circ} \mathrm{C}$.

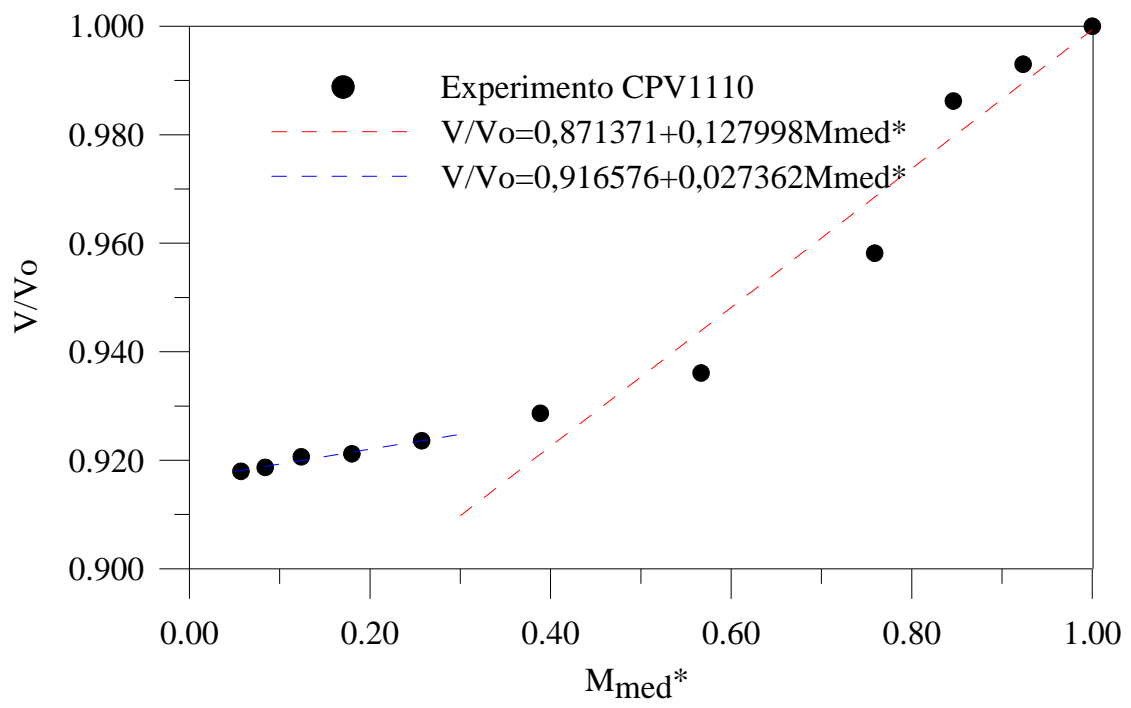

Figura 5: Comparação entre os volumes predito e experimental de tijolos cerâmicos vazados obtidos durante a secagem à $\mathrm{T}=110^{\circ} \mathrm{C}$.

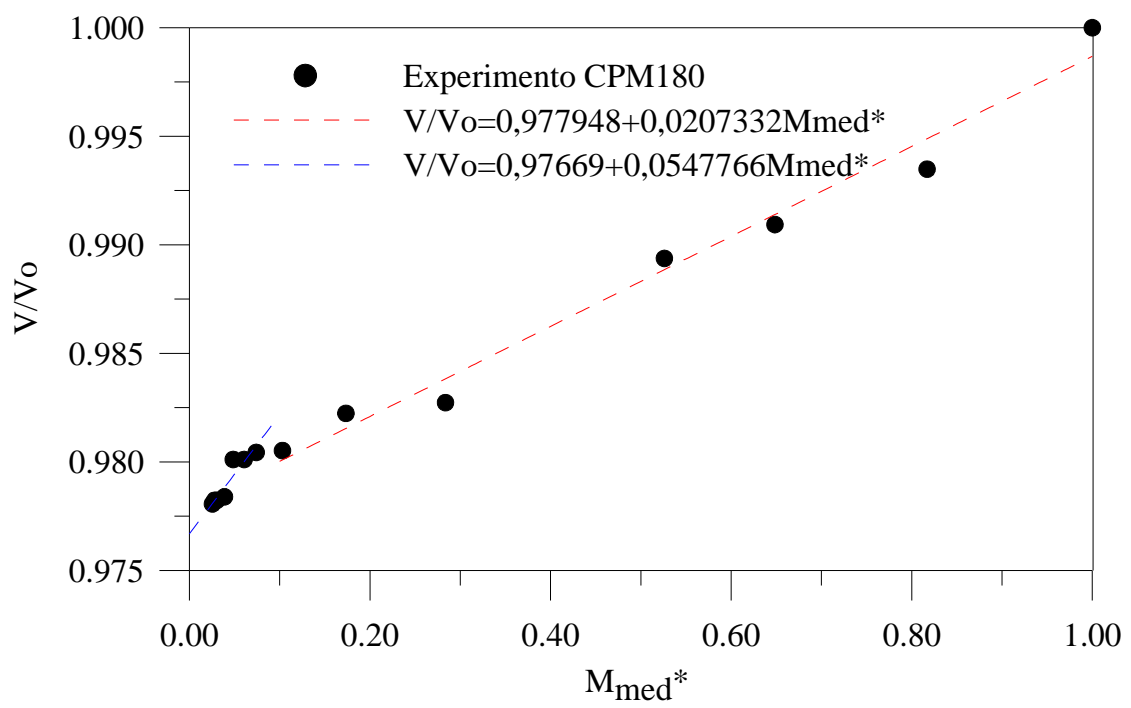

Figura 6: Comparação entre os volumes predito e experimental de tijolos cerâmicos maciços obtidos durante a secagem à $\mathrm{T}=80^{\circ} \mathrm{C}$. 


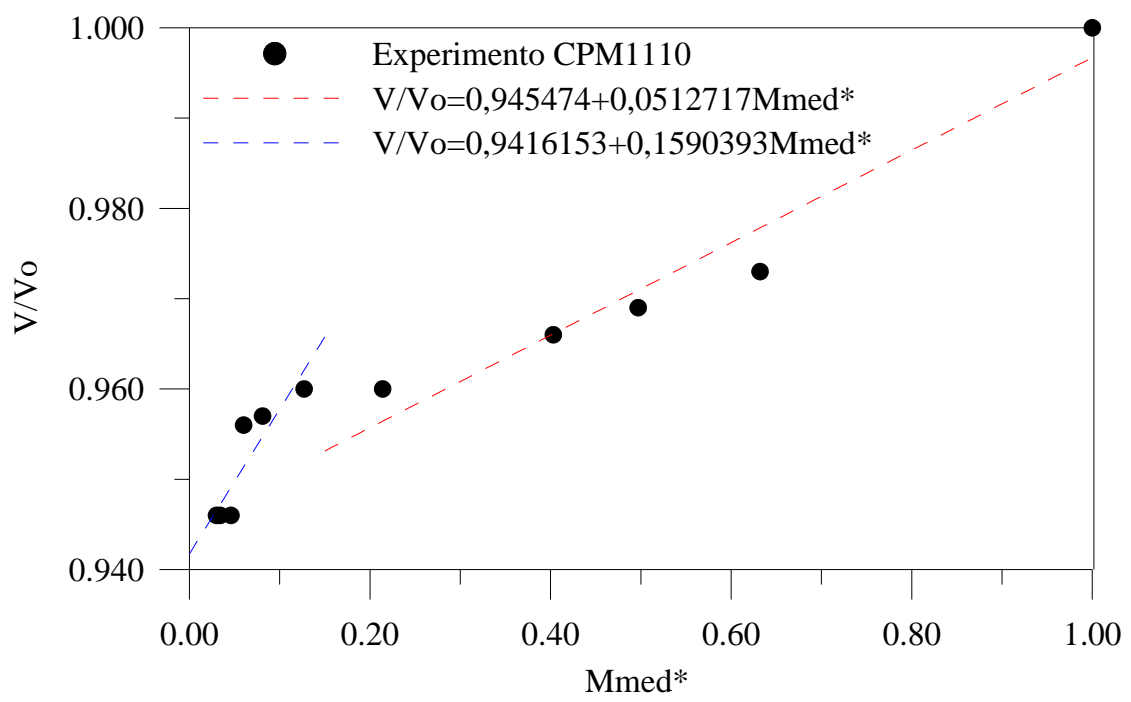

Figura 7: Comparação entre os volumes predito e experimental de tijolos cerâmicos maciços obtidos durante a secagem à $\mathrm{T}=110^{\circ} \mathrm{C}$

\subsection{Cinética de secagem}

Para analisar os efeitos das condições do ar de secagem na redução do teor de umidade dos tijolos cerâmicos, os dados experimentais de teor de umidade em função do tempo para diversas condições de secagem estão plotadas nas Figuras 8 - 11. Por comparação, entre os dados, pode-se ver que a temperatura do ar de secagem tem uma forte influência na taxa de secagem, como esperado. Quando se aumenta a temperatura, a taxa de secagem também aumenta. Isto não é muito desejável porque pode gerar elevados gradientes térmicos na parte interna dos sólidos e então induzir tensões térmica, hídrica e mecânica. Estas tensões podem produzir rachaduras, fissuras e deformações, e contribui para reduzir a qualidade dos tijolos no fim do processo de secagem. De acordo com a literatura [ 6 , 25, 27], o comportamento mecânico da argila geralmente é descrito por viscoelasticidade e plasticidade que por sua vez dependem do teor de umidade.

As formas dos tijolos também afetam a taxa de secagem. Para relações de área/volume mais altas tem-se a velocidade de secagem mais alta e conseqüentemente menos tempo de processo. De acordo com a literatura [14, 27-29], gradientes de umidade e térmicos mais elevados acontecem perto dos vértices do sólido. Então, esta região é mais favorável a rachaduras e fissuras.

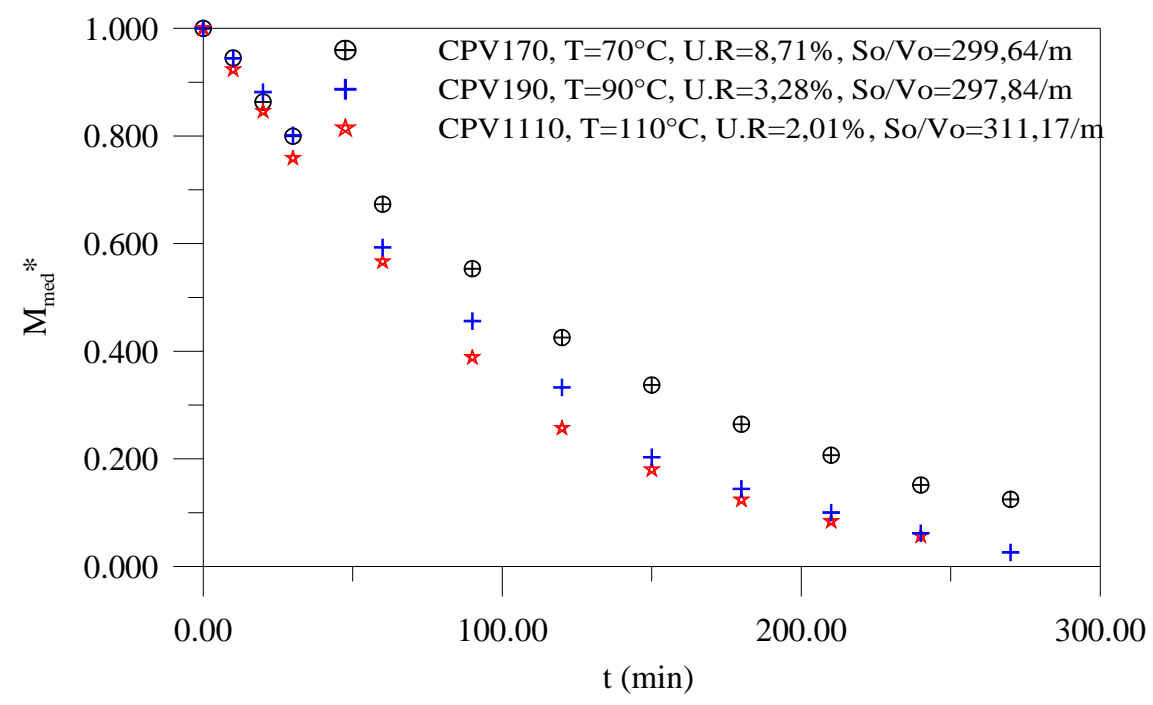

Figura 8: Efeito da temperatura e umidade relativa do ar de secagem na perda de massa (umidade) dos blocos cerâmicos vazados. 


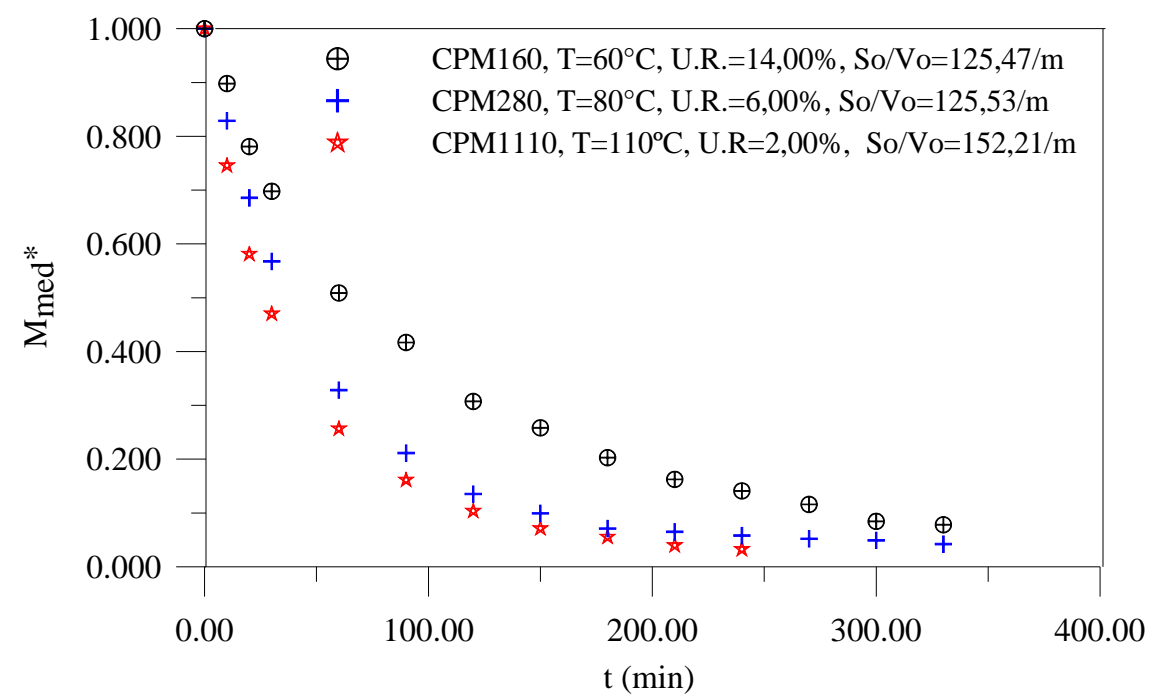

Figura 9: Efeito da temperatura e umidade relativa do ar de secagem na perda de massa (umidade) dos tijolos cerâmicos maciços.

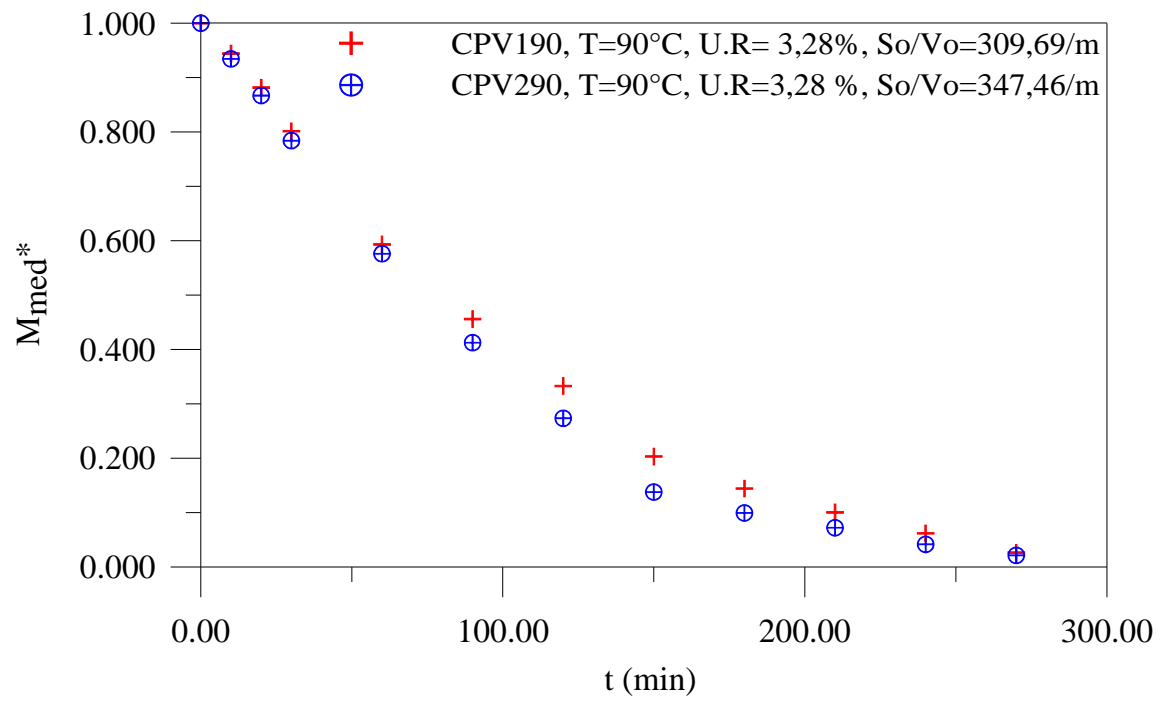

Figura 10: Efeito da relação área / volume (So/Vo) na perda de massa (umidade) para blocos cerâmicos vazados na temperatura de secagem de $90^{\circ} \mathrm{C}$ e umidade relativa de $3,28 \%$.

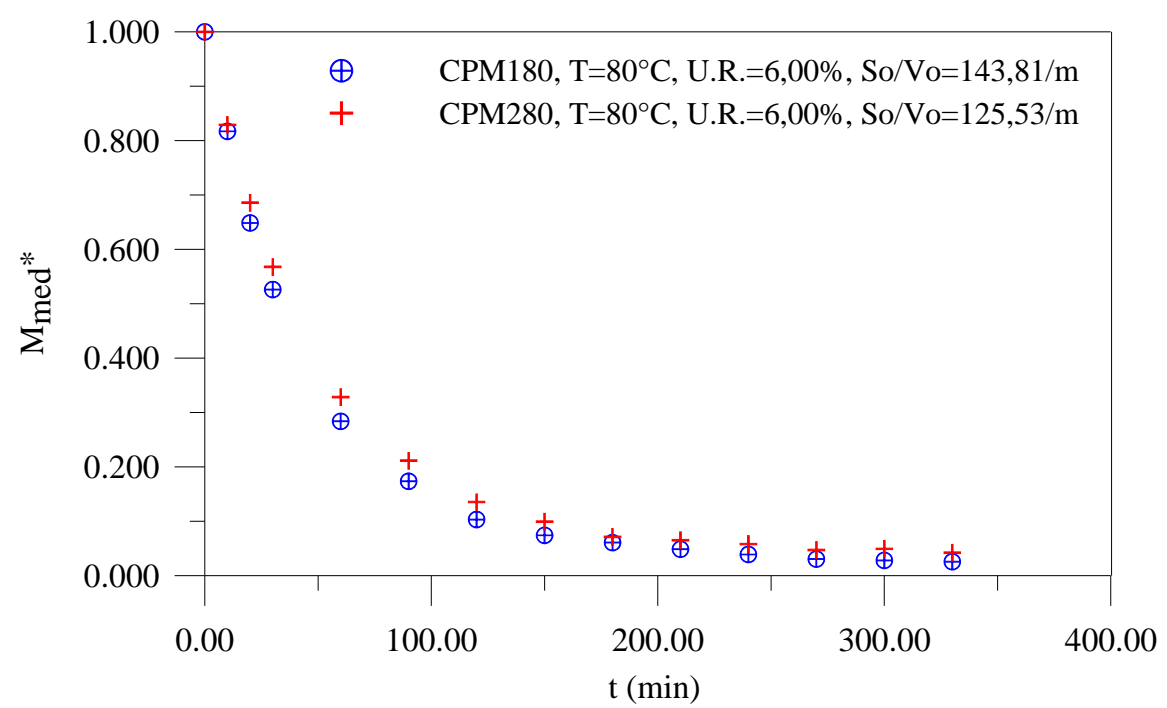

Figura 11: Efeito da relação área / volume (So/Vo) na perda de massa (umidade) para blocos cerâmicos maciços na temperatura de secagem de $80^{\circ} \mathrm{C}$ e umidade relativa de $6,00 \%$. 
Com relação a equação (10), a Tabela 4 apresenta os valores das constantes $A_{i}$ e $K_{i}$ para cada condição de secagem. Como se pode ver foram obtidos excelentes ajustes para cada teste, onde os valores do coeficiente de correlação foram $\mathrm{R}>0,99$.

Tabela 4: Parâmetros da equação (10) para cada condição de secagem.

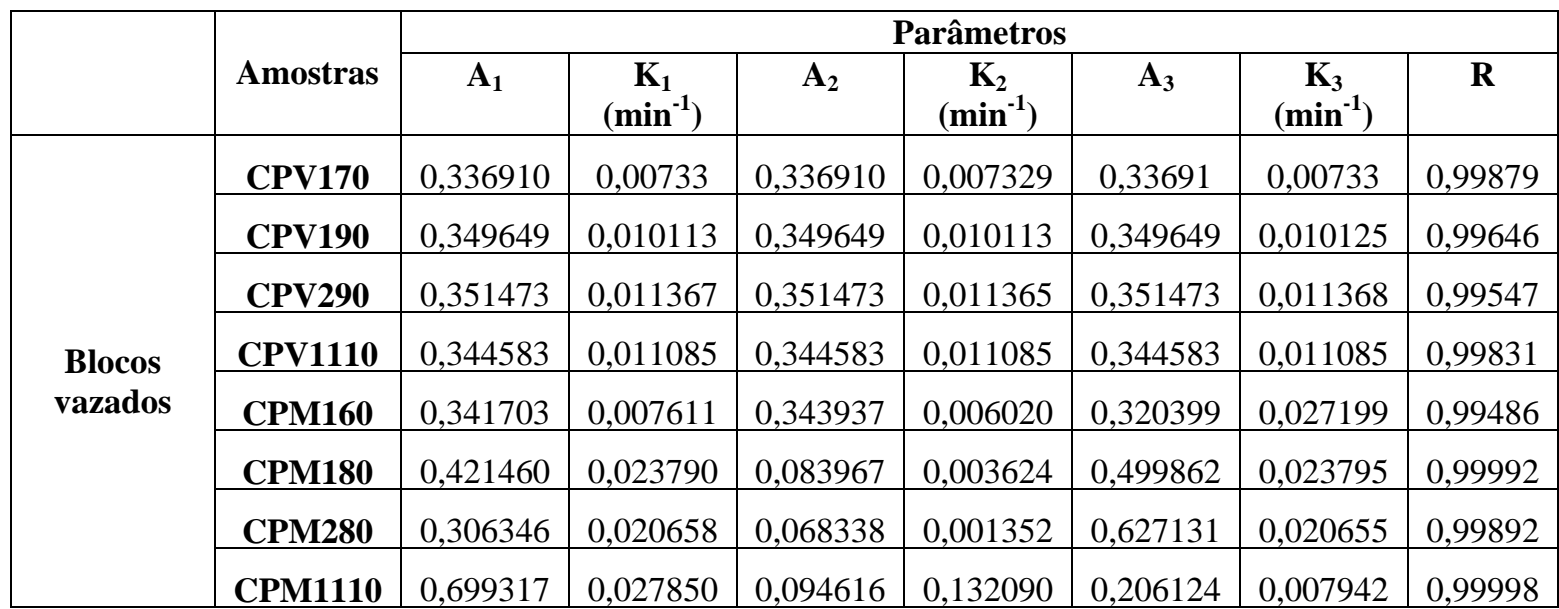

\section{CONCLUSÕES}

Diante dos resultados obtidos neste estudo, podem-se tirar as seguintes conclusões:

- A análise térmica diferencial da argila detectou, devido à liberação de água da argila e mudanças de fase, a presença de água livre e água absorvida, matéria orgânica, hidroxilas, grafite e nucleação da mulita;

- A análise termogravimétrica evidenciou perdas de massa da argila num total de 9,0\%;

- Foram obtidos valores numéricos de coeficientes de encolhimento $\beta_{3}$ e $\beta_{4}$ em várias temperaturas de secagem, nas duas etapas de processo, tanto para tijolos cerâmicos vazados, quanto para tijolos cerâmicos maciços;

- Devido boa correlação entre os pontos experimentais e preditos pela equação proposta para retração volumétrica, conclui-se que a contração volumétrica deve ser mais perfeitamente definida em duas etapas tanto para tijolos maciços quanto vazados;

- A forma do corpo interfere na cinética de secagem; quanto maior a relação área/volume, mais rápida será a secagem;

- Temperaturas do ar de secagem elevadas e umidades relativas baixas implicam numa secagem mais rápida do material. Este efeito é por sua vez, mais acentuado que os gerados pelas relações área/volume e teor de umidade inicial;

- Quando as temperaturas e umidades relativas do ambiente de secagem são as mesmas para corpos de prova com dimensões diferentes, o teor de umidade inicial e a relação área/volume dominam a cinética de secagem;

- Maiores níveis do teor de umidade inicial implica em maiores índices de retração volumétrica;

- A variação do teor de umidade de tijolos cerâmicos maciços e vazados foi bem representada por uma equação exponencial a seis parâmetros devido ao excelente ajuste aos dados experimentais $(\mathrm{R}>0,99)$.

\section{AGRADECIMENTOS}

Ao CNPq, PIBIC/UFCG/CNPq e a FINEP pelo auxílio financeiro e bolsas de Iniciação Científica e PQ, a UFCG/UAEMa/Laboratório de Materiais Maria Cláudia Silva e a UFCG/UAEM/Laboratório Computacional de Térmicas e Fluidos pela infra-estrutura de apoio à pesquisa. 
[1] OLIVEIRA, A.P.N., MONTEDO, O.R.K., PIZETE, J., CASAGRANDE, M., "Matérias-primas empregadas na fabricação de tijolos e blocos de construção: características e influência sobre as propriedades do produto final”, Cerâmica Informação, n. 10, pp. 57-65, Julho/Agosto 2000.

[2] CADÉ, M.A., Secagem de tijolos cerâmicos vazados: modelagem e simulação, Trabalho de Conclusão de Curso, UAEM/Universidade Federal de Campina Grande, Campina Grande, PB, Brasil, 2004.

[3] MEDEIROS, B.L., Secagem de argila com ar quente produzido por radiação solar, Tese de M.Sc., Universidade Federal da Paraíba, João Pessoa, PB, Brasil, 1977.

[4] FRICKE, J., A cerâmica, Lisboa, Ed. Presença Ltda., 1981.

[5] KETELAARS, A.A.J., JOMAA, W., PUIGGALI, J.R., COUMANS, W.J., "Drying shrinkage and stress”, In: Proceeding of the International Drying Symposium, Part A, pp. 293-303, Montreal, August 1992

[6] HASATANI, M., ITAYA, Y., "Deformation characteristic of ceramics during drying”, In: Proceeding of the International Drying Symposium, Part A, pp. 190-199, Montreal, August 1992a.

[7] ELIAS, X., A fabricação de materiais cerâmicos, Barcelona, Espanha, 1995.

[8] REED, J. S., Principles of ceramics processing, 2 ed, New York, USA, Wiley Interscience, 1995.

[9] VAN DER ZANDEN, A.J.J., SCHOENMAKERS, A.M.E, KERKOF, P.J.A.M., "Isothermal vapour and liquid transport inside clay during drying”, Drying Technology, v. 14, n. 3-4, pp. 647-676, March/April 1996.

[10] VAN DER ZANDEN, A.J.J., "Modeling and simulating simultaneous liquid and vapour transport in partially saturated porous materials”, In: TURNER, I., MUJUMDAR, A.S. (eds.), Mathematical Modeling and Numerical Techniques in Drying Technology, New York, USA, Marcel Dekker, Inc., 1997.

[11] VIEIRA, C.M.F., FEITOSA, H.S., MONTEIRO, S.N., "Avaliação da secagem de cerâmica vermelha através da curva de Bigot”, Cerâmica Industrial, v. 8, n. 1, pp. 42-46, Janeiro/ Fevereiro 2003.

[12] NASCIMENTO, J.J.S., BATISTA, V.R., LIMA, A.G.B., "Estudo experimental da secagem de tijolos cerâmicos maciços e vazados”, In: Anais do $51^{\circ}$ Congresso Brasileiro de Cerâmica, pp. 1 - 12, Salvador, BA, Junho 2007.

[13] ALMEIDA, G.S., Simulação e experimentação da secagem de cerâmica vermelha em sistemas térmicos industriais, Tese de D.Sc. (Engenharia de Processos), Universidade Federal de Campina Grande, Campina Grande, PB, Brasil, 2009.

[14] ALMEIDA, G.S., AVELINO, D.O., SILVA, J.B., LIMA, W.C.P.B., NEVES, G.A,; LIMA, A.G.B., "Transporte de calor e massa no interior de secadores industriais de materiais cerâmicos: modelagem e simulação”, In: Anales del Congreso de Metodos Numéricos en Ingeniería, v. 1. p. 120., Barcelona, Junho/Julho 2009.

[15] SILVA, A.A., NASCIMENTO, J.J.S., LIMA, A.G.B., "Estudo analítico de secagem de placas cerâmicas usando o método integral baseado em Galerkin e condição de contorno de Dirichlet”, Revista Eletrônica de Materiais e Processos, v. 4, pp. 48-55, Dezembro 2009.

[16] CADÉ, M.A., NASCIMENTO, J.J.S., LIMA, A.G.B., "Secagem de tijolos cerâmicos vazados: uma aproximação por volumes finitos”, Revista Matéria, v. 10, n. 3, pp. 443-453, 2005.

[17] NASCIMENTO, J.J.S., BELO, F.A., LIMA, A.G.B., "Simultaneous mass transport and shrinkage during drying of solid parallelepiped: a numerical study”, In: Proceedings of the Iberian LatinAmerican Congress on Computational Methods in Engineering, pp. 1-10, Campinas, SP, Novembro 2001a. 
[18] NASCIMENTO, J.J.S., BELO, F.A., "Simultaneous moisture content transport and shrinkage during drying of parallelepiped solids”, In: Proceedings of the Inter-american Drying Conference, v. 1, pp. 331-359, Boca del Rio, Vera Cruz, Mexico, July 2001b.

[19] NASCIMENTO, J.J.S., LIMA, A.G.B., SANTANA, E.W.F., BELO, F.A., NEVES, G.A., SANTANA, L.N.L., BATISTA, V.R., "Experimental drying of ceramic bricks including volumetric retraction", In: Proceedings of the 18th International Congress of Mechanical Engineering, v. 1. pp. 1-10, Ouro Preto, MG, Novembro 2005.

[20] ITAYA, Y., HASATANI, M.R., “R \& D needs - drying of ceramics”, Drying Technology, v. 14, n. 6, pp. 1301-1313, June 1996.

[21] ITAYA, Y., TANIGUCHI, S., HASATANI, M., “A numerical study of transient deformation and stress behavior of a clay slab during drying”, Drying Technology, v.15, n. 1, pp. 1-21, January 1997.

[22] SILVA, J.B., Simulação e experimentação da secagem de tijolos cerâmicos vazados, Tese de Doutorado (Engenharia de Processos), Universidade Federal de Campina Grande, Campina Grande, PB, Brasil, 2009.

[23] NORTON, F.H., Elements of ceramics, Massachusetts, Ed. Addison Wesley, 1975.

[24] LIMA, A.G.B., Diffusion phenomenon in prolate spheroidal solids. Case studied: drying of banana, Ph.D. Thesis, State University of Campinas, Campinas, SP, Brazil, 1999 (In Portuguese).

[25] HASATANI, M., ITAYA, Y., "Effect of drying process on quality control in ceramic production”, In: Proceeding of the International Drying Symposium, Part B, pp. 1181-1198, Montreal, August 1992b.

[26] NASCIMENTO, J.J.S., Fenômenos de difusão em sólidos paralelepípedos. estudo de caso: secagem de materiais cerâmicos, Tese de D.Sc., Universidade Federal da Paraíba, João Pessoa, PB, Brasil, 2002.

[27] HASATANI, M., ITAYA, Y., “Modeling of strain-stress behavior for advanced drying”, In: Proceeding of the International Drying Symposium, pp. 27-39, Krakow, July/August 1996.

[28] AVELINO, D.O., LIMA, A.G.B., "Estudo das tensões durante a secagem de tijolos cerâmicos vazados: modelagem e simulação”, Revista Pesquisa, v. 1, pp. 635-652, 2007.

[29] AVELINO, D.O., SILVA, J.B., ALMEIDA, G.S., NASCIMENTO, J.J.S., LIMA, A.G.B., "Simulação numérica da secagem de tijolos cerâmicos vazados incluindo tensões termo-hidro-mecânicas e variações dimensionais”, In: Anais do V Congresso Nacional de Engenharia Mecânica, v. 1. p. 112, Salvador, BA, Julho 2008. 